\title{
Tidal expiratory flow limitation and chronic dyspnoea in patients with cystic fibrosis
}

\author{
D. Goetghebeur*, D. Sarni*, Y. Grossi*, C. Leroyer*, H. Ghezzo\#, J. Milic-Emili", M. Bellet*
}

Tidal expiratory flow limitation and chronic dyspnoea in patients with cystic fibrosis. D. Goetghebeur, D. Sarni, Y. Grossi, C. Leroyer, H. Ghezzo, J. Milic-Emili, M. Bellet. (C) ERS Journals Ltd 2002.

ABSTRACT: Cystic fibrosis (CF) eventually leads to hyperinflation linked to tidal expiratory flow limitation (FL) and ventilatory failure.

Presence of FL was assessed at rest in 22 seated children and adults with $\mathrm{CF}$ (forced expiratory volume in one second (FEV1) range: 16-92\% predicted), using both the negative expiratory pressure (NEP) technique and the "conventional" method based on comparison of tidal and maximal expiratory flow/volume curves. In addition, chronic dyspnoea was scored with the modified Medical Research Council (MRC) scale. Measurements were made before and 15 min after inhalation of salbutamol.

With NEP, FL was present in only three malnourished patients, who had the lowest FEV1 values (16-27\% pred) and claimed very severe dyspnoea (MRC score 5). By contrast, an additional seven patients were classified as FL with the conventional method. Six of these patients had little or no dyspnoea (MRC scores 0-1). Salbutamol administration had no effect on the extent of FL, and the concomitant decrease in functional residual capacity (FRC) was too small to play any clinically significant role.

This study concluded that in seated patients with cystic fibrosis, expiratory flow limitation is absent at rest, unless the forced expiratory volume in one second is $<30 \%$ predicted. If present, expiratory flow limitation is associated with severe chronic dyspnoea. The conventional method for assessing expiratory flow limitation is not reliable and bronchodilator administration has little effect on expiratory flow limitation. Eur Respir J 2002; 19: 492-498.
*Unité d'Explorations Fonctionelles Respiratoires, Service de Pneumologie, Université de Bretagne Occidentale, Centre Hospitalier Universitaire, Brest, France. ${ }^{\#}$ Meakins-Christie Laboratories, McGill University, Montreal, Canada.

Correspondence: M. Bellet

Unité d'Explorations Fonctionelles

Respiratoires

Hôpital Morvan

29609 Brest

France.

Fax: 33298223959

E-mail: mireille.bellet@univ-brest.fr

Keywords: Body plethysmography, bronchodilator, cystic fibrosis, dynamic hyperinflation, lung function

Received: March 22001

Accepted after revision November 24 2001
Using the negative expiratory pressure (NEP) technique, it has been shown that in patients with chronic obstructive pulmonary disease (COPD) there is a high prevalence of expiratory flow limitation (FL) during resting breathing [1-4]. The presence of tidal FL promotes dynamic pulmonary hyperinflation $(\mathrm{DH})$ and intrinsic positive end-expiratory pressure, with a concomitant increase of inspiratory work, impairment of inspiratory muscle function, and adverse effects on haemodynamics [5]. This contributes to dyspnoea $[2,6]$ and reduces exercise tolerance [3, 7]. Furthermore, in COPD it has been shown that indices based on assessment of $\mathrm{FL}$ are better predictors of chronic dyspnoea (Medical Research Council (MRC) scale) than forced expiratory volume in one second (FEV1) [2] and that the inspiratory capacity (IC), an index of $\mathrm{DH}$, is a better predictor of exercise tolerance than FEV1 [7].

Although cystic fibrosis (CF) may lead to a marked reduction of maximal expiratory flows, particularly at low lung volume [8], which should promote tidal expiratory FL, there are few studies dealing with tidal FL in this disease. Using the NEP technique, BRAGGION et al. [9] found that in asymptomatic CF infants, FL during resting breathing is uncommon. Using the same technique, Pradal et al. [10] studied 12 adults with $\mathrm{CF}$ and found that only two exhibited
FL in the sitting position at rest. However, they did not report the degree of dyspnoea and DH of their patients.

In the present investigation, the NEP technique has been used to assess whether: seated CF patients exhibit FL at rest; presence of FL is associated with $\mathrm{DH}$ measured both in terms of increased functional residual capacity (FRC) and decreased IC [7]; and $\mathrm{FL}$ is associated with chronic dyspnoea, as assessed with the modified MRC dyspnoea scale [2]. Tidal FL was also assessed with the conventional method based on comparison of tidal with maximal flow/ volume curves [11]. Measurements were made before and after the administration of bronchodilator in order to explore whether FL and DH could be reversed.

\section{Methods}

\section{Subjects}

Twenty-two children and young adults with $\mathrm{CF}$ (12 males) were studied. Their anthropometrical characteristics are presented in table 1 . The patients were recruited from the Service de Pédiatrie, Centre Hospitalier Universitaire, Brest and the Centre 
Table 1.-Anthropometric characteristics of patients

\begin{tabular}{lccccc}
\hline $\begin{array}{l}\text { Subject } \\
\text { no. }\end{array}$ & Sex & $\begin{array}{c}\text { Age } \\
\text { yrs }\end{array}$ & $\begin{array}{c}\text { Height } \\
\mathrm{cm}\end{array}$ & $\begin{array}{c}\text { Weight } \\
\mathrm{kg}\end{array}$ & $\begin{array}{c}\mathrm{BMI} \\
\mathrm{kg} \cdot \mathrm{m}^{-2}\end{array}$ \\
\hline $1^{+}$ & $\mathrm{M}$ & 11 & 142 & 33 & 15.1 \\
$2^{+}$ & $\mathrm{F}$ & 14 & 160 & 48 & 18.8 \\
$3^{+}$ & $\mathrm{F}$ & 21 & 158 & 53 & 21.2 \\
$4^{+}$ & $\mathrm{M}$ & 18 & 176 & 56 & 18.1 \\
$5^{+}$ & $\mathrm{F}$ & 11 & 142 & 34 & 18.7 \\
$6^{+}$ & $\mathrm{M}$ & 8 & 113 & 38 & 18.6 \\
$7^{+}$ & $\mathrm{F}$ & 11 & 146 & 34 & 15.7 \\
$8^{+}$ & $\mathrm{M}$ & 11 & 144 & 39 & 18.8 \\
$9^{+}$ & $\mathrm{F}$ & 17 & 150 & 42 & 18.9 \\
$10^{+}$ & $\mathrm{M}$ & 14 & 174 & 50 & 16.5 \\
11 & $\mathrm{~F}$ & 15 & 162 & 47 & 17.9 \\
$12^{+}$ & $\mathrm{M}$ & 15 & 154 & 39 & 16.4 \\
$13^{+}$ & $\mathrm{F}$ & 14 & 134 & 35 & 19.5 \\
14 & $\mathrm{M}$ & 20 & 176 & 53 & $17.1^{\#}$ \\
$15^{+}$ & $\mathrm{M}$ & 18 & 160 & 45 & $17.6^{\#}$ \\
$16^{+}$ & $\mathrm{F}$ & 21 & 158 & 42 & $16.8^{\#}$ \\
17 & $\mathrm{~F}$ & 10 & 142 & 27 & $13.4^{\#}$ \\
$18^{+}$ & $\mathrm{M}$ & 12 & 144 & 29 & $14.0^{\#}$ \\
$19^{+}$ & $\mathrm{M}$ & 6 & 115 & 20 & 15.1 \\
20 & $\mathrm{~F}$ & 15 & 157 & 44 & 17.9 \\
21 & $\mathrm{M}$ & 22 & 162 & 58 & 22.1 \\
22 & $\mathrm{M}$ & 30 & 160 & 65 & 25.4 \\
Mean \pm SD & & $15 \pm 5$ & $151 \pm 16$ & $42 \pm 11$ & $17.9 \pm 2.7$ \\
\hline & & & & &
\end{tabular}

BMI: body mass index. \#: BMI below normal limits, according to normal lifetime variation in BMI prepared by Institut National de la Santé et de la Recherche Médicale, Paris, France [12]; ${ }^{+}$: patients who underwent the bronchodilator test.

Hélio-Marin de Roscoff, Brittany over the period of 1999-2000. In all patients, CF had been diagnosed by at least two positive sweat tests in the presence of compatible clinical findings or familial history [13]. The inclusion criteria were: an age $>5$ yrs; the ability to perform lung function tests reliably; a stable clinical condition; no use of bronchodilators in the 6-h period before testing, except in patients treated with long-acting bronchodilators who were asked to refrain from use for at least $24 \mathrm{~h}$. The therapeutic regimen at the time of the study included an appropriate diet with pancreatic enzyme replacement, vitamins, chest physiotherapy after the inhalation of nebulized saline solution twice a day, and antibiotic maintenance therapy. The research was approved by the institutional Ethics Committee, and informed consent for the study was obtained from the patients or their parents.

\section{Lung function}

The pulmonary function tests were performed after physiotherapy in accordance with the American Thoracic Society (ATS) standardized guidelines [14], and were expressed as per cent predicted (\% pred) normal values for adults of the European Community for Steel and Coal [15] and for children, according to ZAPLETAL et al. [16]. The forced vital capacity (FVC) manoeuvres were performed after a rapid maximal inspiration from FRC to total lung capacity (TLC) without an end-inspiratory hold [17].
Thoracic gas volume (TGV) at FRC was measured in a constant-volume whole body plethysmograph (1085 DX System; Medical Graphics, St. Paul, MN, USA).

\section{Dyspnoea}

The severity of chronic dyspnoea was rated according to the modified MRC scale, which ranges from score zero (no dyspnoea) to score 5 (very severe dyspnoea: too breathless to leave the house or breathlessness when dressing or undressing) [2].

\section{Expiratory flow limitation}

Assessment of tidal FL was made using: 1) the NEP technique [2, 4] and 2) the "conventional" method of superimposition of tidal with maximal expiratory flow/volume $\left(V^{\prime} / V\right)$ curves [11]. In this case, volume was measured with the body plethysmograph to avoid errors due to thoracic gas compression [18]. The experimental set-up used to assess FL by NEP (Raytech Instruments, Vancouver, Canada) has been previously described in detail [2]. The dead space of the equipment assembly was $<30 \mathrm{~mL}$, and its pressure/ flow relationship was characterized by the following equation:

$$
P=0.85 V^{\prime}+0.7 V^{\prime 2}
$$

where pressure $(P)$ is in $\mathrm{cmH}_{2} \mathrm{O}$ and flow $\left(V^{\prime}\right)$ in $\mathrm{L} \cdot \mathrm{s}^{-1}$. During the NEP trials, $V^{\prime}$ was measured with a Hans-Rudolph pneumotachograph with a $\pm 2.6 \mathrm{~L} \cdot \mathrm{s}^{-1}$ linearity range (model 4700A; Hans-Rudolph, Kansas City, MO, USA) connected to a differential pressure transducer (MP45, $\pm 2 \mathrm{cmH}_{2} \mathrm{O}$; Validyne Northridge, CA, USA). Artifacts on the flow record caused by common-mode rejection ratio (CMRR) were negligible. Volume was obtained by numerical integration of the $V^{\prime}$ signal. Pressure at the airway opening ( $P$ ao $)$ was measured through a side port on the mouthpiece with a differential pressure transducer (Validyne MP45, $\pm 100 \mathrm{cmH}_{2} \mathrm{O}$ ). The system used to measure $P$ ao had no appreciable shift or alteration in amplitude $\geqslant 20 \mathrm{~Hz}$. The pressure, flow and volume signals were amplified, low-pass filtered $(50 \mathrm{~Hz})$ and digitized at $100 \mathrm{~Hz}$ by a 16-bit analog-to-digital converter (Direc Physiologic Recording System; Raytech Instruments). The digitized data were stored on a computer hard disk for subsequent analysis. Data analysis was performed using Direc software (version 3.1; Raytech Instruments) and Anadat software (version 5.1; RTH InfoDat Inc., Montreal, Canada).

\section{Procedure and data analysis}

The patients were studied in the afternoon sitting upright. All 22 patients underwent spirometric and plethysmographic lung function measurements, including assessment of tidal FL both with the NEP and conventional method. In the 16 patients treated with short-acting bronchodilators (table 1), 
the measurements were performed both before and $15 \mathrm{~min}$ after the administration of $400 \mu \mathrm{g}$ of salbutamol through a metered-dose inhaler and an inhalation chamber.

For assessment of FL with NEP, the subjects were asked to breathe room air through the equipment assembly while wearing a noseclip. Each subject had an initial 5-min trial in order to become accustomed to the apparatus and procedure. After regular breathing had been achieved, a series of test breaths, in which NEP $\left(-3 \mathrm{cmH}_{2} \mathrm{O}\right)$ was applied near the onset of expiration and was maintained throughout the ensuing expiration, were performed. Analysis of the data obtained with NEP consisted of comparing the expiratory $V^{\prime} / V$ curve of a control tidal expiration with that obtained during the subsequent expiration, in which NEP was applied. Subjects in whom application of NEP did not elicit an increase of flow over part or all of the control tidal expiration were classified as FL. By contrast, subjects in whom flow increased with NEP over the entire range of the control tidal expiration were considered as not flow limited (NFL). The FL portion of the expired volume was expressed as a percentage of the control tidal volume (FL, \% VT) [2].

FL was also assessed by superimposition of the tidal and maximal expiratory $V^{\prime} / V$ curves [11]. Volume was measured with the body plethysmograph to avoid artifacts due to thoracic gas compression [18]. With this method, defined as the conventional method, patients in whom, at comparable lung volume, flows during tidal expiration were similar to or higher than those obtained during the FVC manoeuvre were considered as FL.

\section{Statistical analysis}

Data are expressed as mean \pm SD. Results obtained before and after bronchodilator administration were compared with the paired t-test or Wilcoxon signedrank test, where appropriate. Linear regressions were assessed with the least square method. The curves relating the MRC dyspnoea score to IC and FEV1 were also computed by robust, locally-weighted regression and smoothing analysis [19]. The tension parameter (bandwidth) used for averaging was twothirds of the data $(n=22)$. A $p$-value of $<0.05$ was considered significant.

\section{Results}

Twenty-two CF patients (12 males), aged 6-30 yrs, were included in the study. All were nonsmokers. The anthropometric and lung function data are listed in table 1. The study population encompassed the spectrum of mild (FEV1 $>80 \%$ pred) to severe lung disease (FEV1 $<40 \%$ pred) (table 2 ). In line with previous reports $[8,12,16]$, the average values of FEV1 and FVC were lower than the predicted normal, TLC was within normal limits, and residual volume (RV) and FRC were increased, reflecting gas trapping and hyperinflation. The IC was below the normal limits in 12 of the patients, reflecting $\mathrm{DH}$ in line with

Table 2. - Lung function data and chronic dyspnoea score

\begin{tabular}{|c|c|c|c|c|c|c|c|c|c|}
\hline Subject & FEV1 & FVC & $\mathrm{FEV}_{1 / \mathrm{FVC}}$ & MEF25 & $\mathrm{IC}$ & FRC & RV & TLC & MRC score \\
\hline 1 & 59 & 80 & 76 & 25 & 67 & 157 & 199 & 105 & 0 \\
\hline $2^{\#}$ & 53 & 69 & 74 & 10 & 88 & 153 & 288 & 119 & 0 \\
\hline 3 & 76 & 89 & 85 & 31 & 114 & 98 & 144 & 105 & 0 \\
\hline 4 & 66 & 67 & 95 & 49 & 76 & 101 & 161 & 87 & 0 \\
\hline $5^{\#}$ & 71 & 85 & 76 & 16 & 67 & 163 & 192 & 107 & 0 \\
\hline $6^{\#}$ & 54 & 66 & 64 & 10 & 75 & 173 & 307 & 116 & 0 \\
\hline 7 & 79 & 74 & 103 & 61 & 74 & 85 & 113 & 82 & 0 \\
\hline 8 & 85 & 104 & 82 & 29 & 100 & 150 & 186 & 121 & 0 \\
\hline $9^{\#}$ & 43 & 72 & 66 & 11 & 86 & 78 & 111 & 82 & 0 \\
\hline 10 & 69 & 80 & 77 & 17 & 75 & 145 & 196 & 104 & 0 \\
\hline 11 & 49 & 58 & 84 & 13 & 67 & 109 & 184 & 87 & 1 \\
\hline 12 & 33 & 75 & 47 & 6 & 66 & 290 & 487 & 160 & 3 \\
\hline 13 & 88 & 93 & 96 & 37 & 86 & 123 & 137 & 103 & 1 \\
\hline 14 & 40 & 74 & 65 & 14 & 68 & 143 & 219 & 103 & 0 \\
\hline 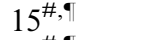 & 16 & 28 & 69 & 6 & 33 & 125 & 261 & 78 & 5 \\
\hline $16^{\#, 9}$ & 26 & 32 & 82 & 7 & 52 & 131 & 276 & 96 & 5 \\
\hline 17 & 92 & 95 & 101 & 55 & 99 & 109 & 134 & 104 & 0 \\
\hline $18^{\#,-\oplus}$ & 27 & 49 & 64 & 7 & 50 & 221 & 412 & 134 & 5 \\
\hline 19 & 93 & 100 & 89 & 44 & 107 & 135 & 180 & 120 & 0 \\
\hline $20^{\#}$ & 81 & 99 & 83 & 12 & 99 & 122 & 149 & 110 & 1 \\
\hline 21 & 87 & 110 & 77 & 38 & 118 & 133 & 182 & 126 & 2 \\
\hline $22^{\#}$ & 45 & 74 & 67 & 11 & 84 & 91 & 129 & 87 & 0 \\
\hline Mean \pm SD & $61 \pm 23$ & $76 \pm 21$ & $78 \pm 14$ & $22 \pm 16$ & $80 \pm 21$ & $138 \pm 47$ & $211 \pm 95$ & $106 \pm 19$ & $1.05 \pm 2$ \\
\hline
\end{tabular}

FEV1: forced expiratory volume in one second; FVC: forced vital capacity; MEF25: maximal expiratory flow at $25 \%$ of the vital capacity; IC: inspiratory capacity; FRC: functional residual capacity; RV: residual volume; TLC: total lung capacity; MRC: Medical Research Council. Except for MRC chronic dyspnoea score, all values are expressed as per cent of predicted normal. " : flow limited according to "conventional" method; ": flow limited according to negative expiratory pressure test. 


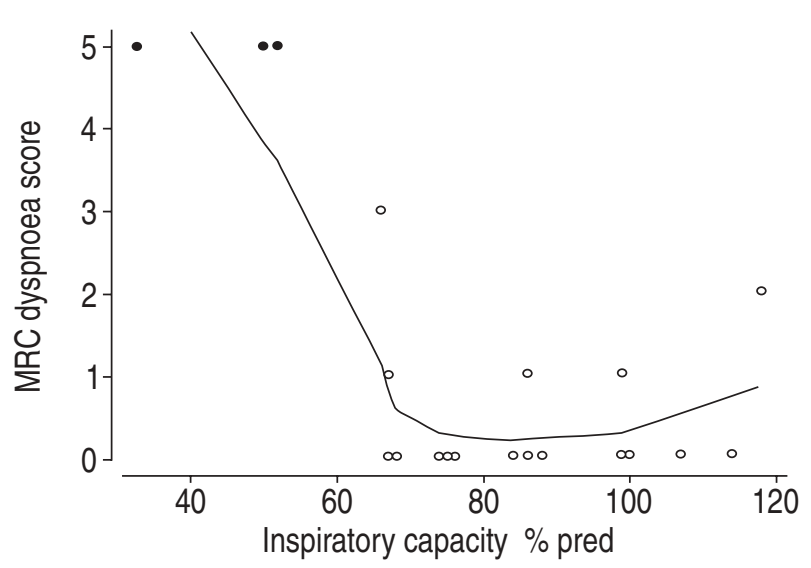

Fig. 1.-Relationships of Medical Research Council (MRC) dyspnoea score to inspiratory capacity in cystic fibrosis patients. The curve was computed by robust, locally-weighted regression and smoothing analysis. \% pred: \% predicted. 0 : flow limited; $\bigcirc$ : not flow limited according to the negative expiratory pressure test. The coefficient of determination $\left(\mathrm{r}^{2}\right)=0.8 ; \mathrm{p}<0.0001$.

previous reports $[9,12,16]$. The maximal expiratory flows at $25 \%$ of the vital capacity (VC) (MEF25) were markedly reduced. There was a wide variability in lung function between subjects.

Chronic dyspnoea was not a problem in 14 (64\%) of the patients in whom the MRC dyspnoea score was 0 (not troubled by dyspnoea). In three patients, the degree of dyspnoea was slight (MRC score 1) and in another moderate (MRC score 2). Only four patients claimed moderately severe to very severe dyspnoea (Patient nos. 12, 15, 16 and 18). These four patients had the lowest values of FEV1 (ranging from $16-33 \%$ pred) and MEF25 (6-7\% pred). They also exhibited the lowest IC values $(33-66 \%$ pred. Their age ranged from 12-21 yrs.

Based on linear regression analysis, the MRC dyspnoea score correlated significantly with the normalized values of IC (the coefficient of determination $\left(r^{2}=0.35 ; p<0.001\right)$ and FEV1 $\left(r^{2}=0.40 ; p<0.001\right)$. As shown in figures 1 and 2 , however, it is obvious that the relationships of MRC dyspnoea score to IC and FEV1 are not linear, and that a significant increase in dyspnoea score only occurs when the IC and FEV1 fall below a critical threshold value. Accordingly, the curves in figures 1 and 2 were computed by robust, locally-weighted regression and smoothing analysis. Based on this analysis, $\mathrm{r}^{2}$ for IC and FEV 1 both amounted to 0.8 , a value considerably higher than those pertaining to the linear regression analysis (as discussed earlier). Analysis of figures 1 and 2 shows that the critical threshold values for IC and FEV1 amount to 70 and 50\% pred normal, respectively. The similarity of the relationships in figures 1 and 2 reflects the fact there was a close correlation between IC and FEV1 $\left(r^{2}: 0.65 ; p<0.001\right)$.

\section{Expiratory flow limitation}

With the NEP method, only three patients (nos. 15, 16 and 18) had an FL under baseline conditions, the FL encompassing virtually the entire control $V$ T

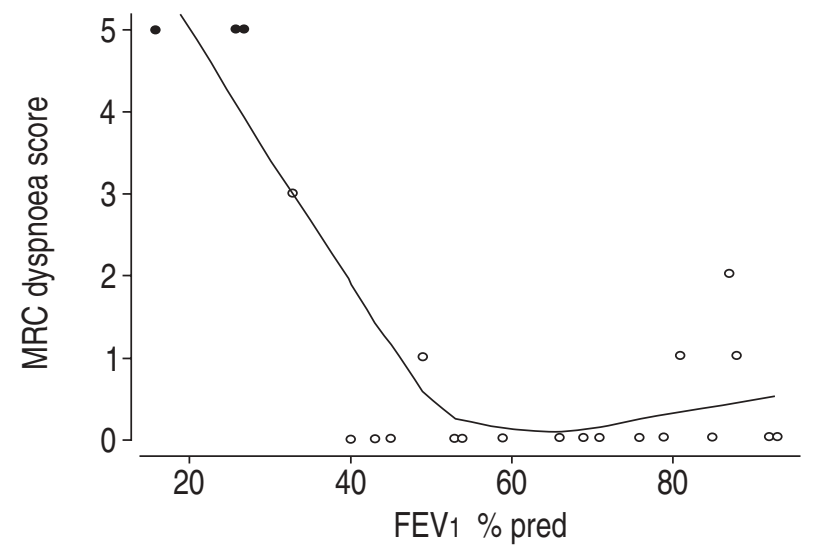

Fig. 2.-Relationships of Medical Research Council (MRC) dyspnoea score to forced expiratory volume in one second (FEV1) in cyctic fibrosis patients. The curve was computed by robust, locally-weighted regression and smoothing analysis. $\%$ pred: $\%$ predicted. 0 : flow limited; $\bigcirc$ : not flow limited according to the negative expiratory pressure test. The coefficient of determination $\left(\mathrm{r}^{2}\right)=0.8 ; \mathrm{p}<0.0001$.

(fig. 3). These three patients exhibited the highest MRC dyspnoea scores (5, very severe), and the lowest IC (range: $33-52 \%$ pred) and FEV1 (range: 16-27\% pred) found in this patient population, and had a decreased body mass index (BMI) due to malnourishment and maldigestion (table 1).

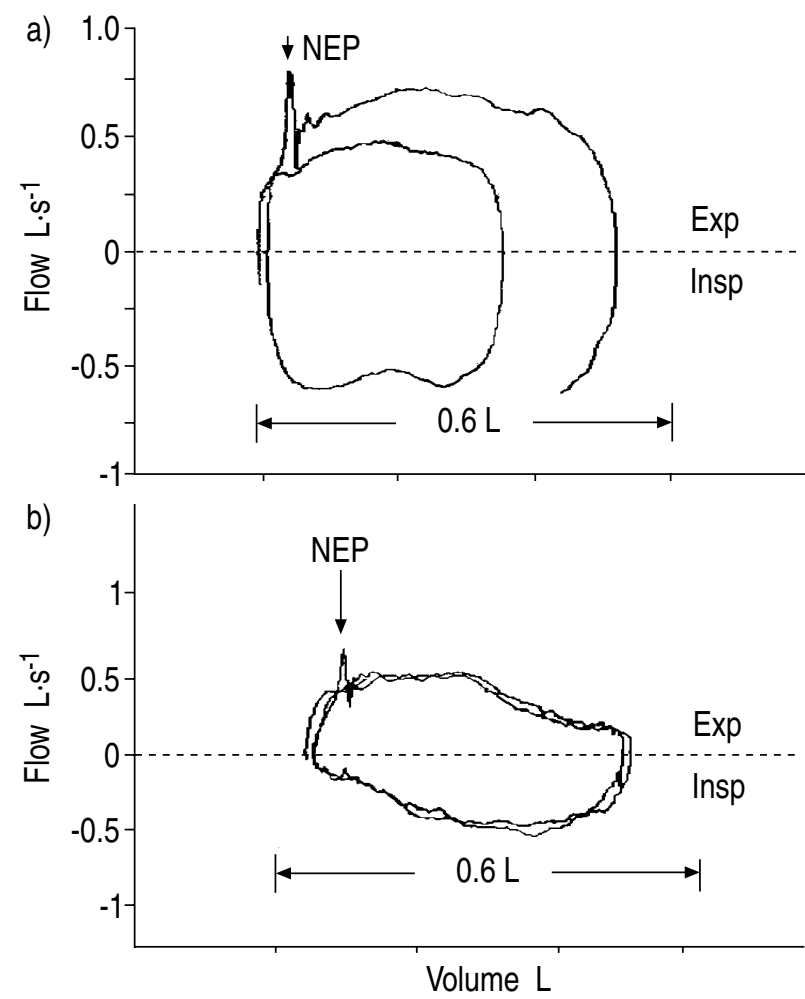

Fig. 3.-Flow/volume loops of negative respiratory pressure (NEP) test breaths and preceding control breaths of a patient a) without (patient no. 5) and b) a patient with expiratory flow limitation encompassing the entire control tidal volume (patient no. 15). Arrows indicate point at which NEP $\left(-3 \mathrm{cmH}_{2} \mathrm{O}\right)$ was applied. Exp: expiratory; Insp: inspiratory. 


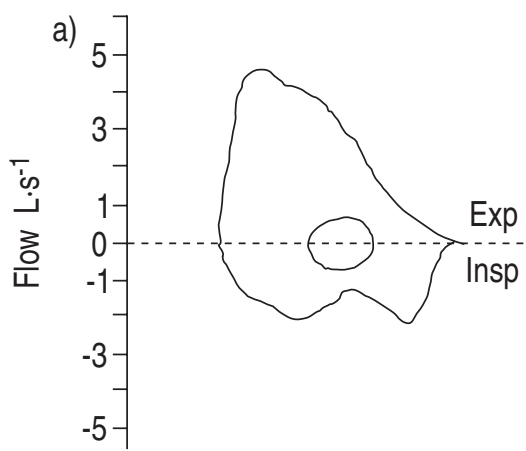

Volume L

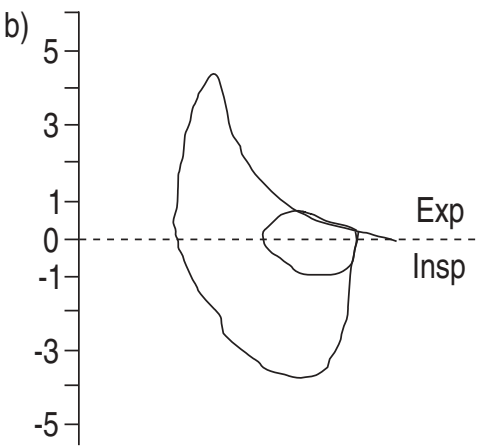

Volume L

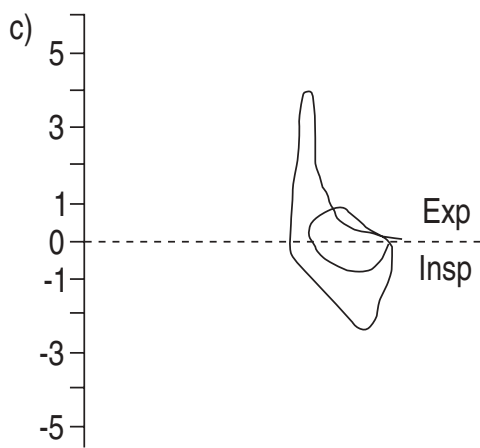

Volume L

Fig. 4. - Tidal and maximal flow/volume curves of three representative cystic fibrosis patients. Compared to maximal, the tidal expiratory flows are a) lower in type 1 (patient $8, n=12$ ), b) superimposed in type 2 (patient $2, n=5$ ), and c) higher in type 3 (patient 15 , n=5). Conventionally, the type 1 pattern indicates absence of tidal flow limitation, while the other two patterns are taken to indicate presence of tidal flow limitation. Exp: expiratory; Insp: inspiratory.

Tidal FL was also assessed by comparing the resting and maximal expiratory $V^{\prime} / V$ curves [11]. Assuming that, at comparable volumes, similar or higher flows during resting expiration than during the FVC manoeuvre reflect tidal FL (types 2 and 3 in fig. 4), 10 patients would be classified as FL (nos. 2, 5, 6, 9, 12 , 15, 16, 18, 20, 22). Their FEV1 and IC ranged, respectively, from $16-81$ and 33-99\% pred normal. Only three of these patients, all with type 3 pattern, were found to be FL with the NEP method (nos. 15, 16, 18).

\section{Effects of salbutamol}

The FEV1 increased significantly $(\mathrm{p}<0.02)$ after inhalation of salbutamol (table 3), but only two patients (nos. 9 and 18) were responders to bronchodilator according to the ATS standards [20]. After salbutamol, there was a significant $(\mathrm{p}<0.01)$ decrease of FRC while FVC and IC did not change. The three patients, who with NEP were classified as FL under baseline conditions, remained FL after salbutamol administration $(\mathrm{FL}>90 \% V \mathrm{~T})$. The same was true for the 10 patients who were classified as FL according to the conventional method. In all of them, FL persisted after salbutamol.

Table 3.-Lung function data $15 \mathrm{~min}$ before and after inhalation of salbutamol

\begin{tabular}{lllc}
\hline & $\begin{array}{c}\text { Before } \\
\text { salbutamol }\end{array}$ & $\begin{array}{c}\text { After } \\
\text { salbutamol }\end{array}$ & $\begin{array}{c}\text { Per cent } \\
\text { change }\end{array}$ \\
\hline FEV1 L & $1.48 \pm 0.70$ & $1.53 \pm 0.71^{\#}$ & $4 \pm 9$ \\
FVC L & $2.16 \pm 0.87$ & $2.23 \pm 0.84$ & $5 \pm 9$ \\
IC L & $1.58 \pm 0.62$ & $1.59 \pm 0.53$ & $2 \pm 11$ \\
FRC L & $2.64 \pm 1.05$ & $2.56 \pm 0.99^{\bullet}$ & $-4 \pm 6$ \\
\hline
\end{tabular}

Data are presented as mean $\pm \mathrm{SD}$, unless otherwise stated. FEV1: forced expiratory volume in one second; FVC: forced vital capacity; IC: inspiratory capacity; FRC: functional residual capacity. Significant change after salbutamol. ${ }^{\#}: \mathrm{p}<0.02 ; \uparrow^{\prime}: \mathrm{p}<0.01$. $\mathrm{n}=16$.

\section{Discussion}

The results of the present investigation suggest that in $\mathrm{CF}$ patients severe chronic dyspnoea and tidal FL during resting breathing in sitting position are uncommon, being present only when the FEV1 is $<50 \%$ pred normal. In addition, the results indicate that assessment of FL based on comparison of tidal and maximal $V^{\prime} / V$ curves is also not valid in $\mathrm{CF}$ patients, even if the measurements are made using a body plethysmograph [18].

According to the NEP technique only three (14\%) of the CF patients were FL during resting breathing in sitting position. With the NEP technique, a low prevalence of FL had been previously found by BRAGGION et al. [9] in 10 asymptomatic CF infants, and by Pradal et al. [10] in 12 stable CF adults (FEV1 range $19-110 \%$ pred). In contrast, in stable COPD patients there is a high prevalence of tidal FL [1-3]. Indeed, using the NEP technique, 69 (59\%) out of 117 stable COPD patients were found to be FL during resting breathing in sitting position [2]. However, it should be noted that, in these COPD patients, the FEV1 was lower than in the CF patients in the present study (on average, 40 versus $61 \%$ pred). Indeed, all three of the CF patients with FEV $1<30 \%$ pred were FL. However, none of the $13 \mathrm{CF}$ patients with FEV1 ranging $40-79 \%$ pred were FL according to the NEP test. In contrast, $28 \%$ COPD patients with FEV1 in the same range were found to be FL sitting at rest [2]. This discrepancy between CF and COPD may reflect a greater loss of lung elastic recoil and more peripheral lung disease in the latter condition. Conversely, as in asthma [21], the low prevalence of FL in $\mathrm{CF}$ patients could be due to persistent tonic contraction of the inspiratory muscles during expiration with a concomitant increase of the end-expiratory lung volume (EELV) sufficient to avoid tidal FL [22-24]. Such a mechanism may explain the fact that in nine of the $\mathrm{CF}$ patients the $\mathrm{IC}$ was reduced below the normal limits (range: $66-76 \%$ pred) in the absence of FL. The decreased IC in the NFL patients, however, could also reflect a prolonged time constant of the respiratory system such that during tidal 
expiration there was not enough time to bring the respiratory system to its relaxation (elastic equilibrium) volume [21, 22]. In this connection, it should be noted that in stable COPD patients a reduction of IC below the normal limits only occurs when tidal FL is present [7]. This clearly is not the case in CF patients with mild-to-moderately severe obstruction (FEV $1>40 \%$ pred), in whom the IC may be reduced in the absence of FL. However, in the three patients with severe CF (FEV1 $<30 \%$ pred), in whom tidal FL was present, there was a more marked reduction of IC (range: $33-52 \%$ pred).

In $78 \%$ of the $\mathrm{CF}$ patients in this study, chronic dyspnoea was slight or absent (MRC scores 0 or 1), in one patient moderate (score 2) and in another moderately severe (score 3 ). Only three FL patients, had very severe dyspnoea (score 5). Whether presence of tidal FL in CF patients results in a critical stage of the disease, characterized by severe disability, needs to be confirmed by follow-up studies on the same patients. In general, stable patients with asthma also exhibit little or no chronic dyspnoea [21], while in stable COPD patients, dyspnoea tends to be more severe [2].

Since, according to NEP, only three of the study patients exhibited tidal FL, it was not possible to conclude whether FL is associated with chronic dyspnoea, which was the third aim of the present study.

In the present subjects, there was a significant correlation $\left(\mathrm{r}^{2}=0.80 ; \mathrm{p}<0.0001\right)$ between the MRC dyspnoea score and IC (\% pred) (fig. 1). Since in COPD patients the exercise tolerance has been shown to be closely correlated to IC [7] and the MRC dyspnoea score basically reflects the exercise capacity, it is not surprising that there is a correlation between the MRC dyspnoea score and IC. A significant correlation was also found between the MRC dyspnoea score and FEV1 (\% pred) (fig. 2), reflecting the close association between IC and FEV1 $\left(\mathrm{r}^{2}=0.65 ; \mathrm{p}<0.001\right)$.

In accordance with previous reports [3, 10, 21, 25], it was confirmed that assessment of FL based on comparison of tidal with maximal $V^{\prime} / V$ curves is inaccurate. Based on the latter approach, 10 of the patients would have been considered FL, whereas according to the NEP technique only three of them were actually FL. The discrepancy between results obtained with NEP and the conventional method is predictable in view of: the different volume and time history during resting breathing compared to the FVC manoeuvre [1, 3, 16, 21, 25]; the time-constant inequality within the diseased lungs [26] and the fact that in $\mathrm{CF}$ patients forced expiratory manoeuvres commonly provoke cough, which additionally influences the volume and time history. Since the volume and time history during resting breathing is different from that pertaining to the FVC manoeuvre, it is axiomatic that detection of tidal FL with the conventional method is problematic even when measurements are made using a body plethysmograph in order to avoid artifacts due to thoracic gas compression [18]. In fact, using the latter technique in five of the CF patients, the expiratory flows during tidal expiration were higher than during the FVC manoeuvre (type 3 in fig. 4). Such a phenomenon, which has been amply described in previous reports [1, $3,21,25]$, indicates that the conventional method for assessing FL is definitely not reliable because tidal flows would not be expected to exceed the "maximal" flows. No such problems pertain to the NEP method because the control and NEP test breaths have a similar volume and time history. Furthermore, the NEP method does not require either a body plethysmonograph or patient cooperation and coordination. It should be stressed that the presence of tidal FL in the sitting position implies a marked disability, characterized by reduced exercise capacity and severe chronic dyspnoea [2, 3, 5, 7]. However, in five of the six CF patients in whom the conventional method for assessing FL gave false positive results (i.e. FL was absent according to the NEP method), chronic MRC dyspnoea was either slight or absent (scores 1-0) and the FEV1 was as high as $81 \%$ pred. This is in accordance with previous results obtained in patients with stable asthma [21] and in COPD patients after single lung transplantation [25].

\section{Effects of salbutamol}

After inhalation of salbutamol, there was a small though significant increase of FEV1 (table 3). Only two patients (nos. 9 and 18) increased the FEV1 by $>12 \%$, and hence were "responders" according to the ATS standards [20]. After salbutamol administration, there was also a small reduction of FRC $(\mathrm{p}<0.02)$. Nevertheless, all three patients who were FL before the administration of salbutamol also remained FL after administration (FL $>90 \%$ ). Similar results have been found by PradAL et al. in adult CF patients [10]: the two subjects who were FL in sitting position before inhalation of salbutamol also remained FL after. However, these authors also assessed FL in the supine position; out of the four CF patients who prior to salbutamol were FL in the supine but not sitting position, three became NFL after salbutamol and one reduced FL from 100 to $10 \% V$ T.

\section{Clinical implications}

The results of the present study suggest that chronic dyspnoea should be routinely assessed in CF patients. Chronic dyspnoea is easily assessed with the 6-point MRC dyspnoea questionnaire, which is simple and reliable [2]. Although both IC and FEV1 should provide important information on the status and progress of the disease, measurement of IC seems to be particularly useful because in $\mathrm{CF}$ patients the forced expiratory manoeuvres commonly induce cough which makes measurement of FEV1 problematic. Assessment of FL may also be useful for assessing the severity of CF. Further studies, however, are required to confirm this point.

To conclude, in cystic fibrosis patients breathing at rest in sitting position, there was a low prevalence of tidal expiratory flow limitation; only three subjects with severe airway obstruction (forced expiratory 
volume in one second $<30 \%$ pred) exhibited tidal expiratory flow limitation, associated with a severe chronic dyspnoea and a marked reduction of inspiratory capacity, reflecting dynamic pulmonary hyperinflation. A moderately decreased inspiratory capacity was also exhibited by the cystic fibrosis patients with mild to moderately severe airway obstruction, in whom it may have reflected dynamic hyperinflation due to persistent activity of the inspiratory muscles during expiration and/or increased time constant inequality within the lungs. In most of these patients, chronic dyspnoea was slight or absent. Administration of bronchodilator (inhaled salbutamol) had no effect on the extent of tidal flow limitation, but caused a small but significant decrease in functional residual capacity.
9. Braggion C, Polese G, Fenzi V, Carli MV, Pradal U, Milic-Emili J. Detection of tidal expiratory flow limitation in infants with cystic fibrosis: a pilot study. Pediatr Pulmonol 1998; 25: 213-215.

10. Pradal V, Polese G, Braggion C, Milic-Emili J. Reversibility of expiratory flow limitation in patients with cystic fibrosis. Pediatr Pulmonol 1998; 17: 341.

11. Hyatt RE. The interrelationship of pressure, flow and volume during various respiratory maneuvers in normal and emphysematous patients. Am Rev Respir Dis 1961; 83: 676-683.

12. De Meer K, Gulmans VAM, van der Laag J. Peripheral muscle weakness and exercise capacity in children with cystic fibrosis. Am J Respir Crit Care Med 1999; 159: 748-754.

13. Wood RE, Boat TF, Doersuk CF. Cystic fibrosis: state of the art. Am Rev Respir Dis 1976; 113: 833-878.

14. American Thoracic Society. Standardization of spirometry. Am Rev Respir Dis 1987; 136: 1285-1298.

15. European Community for Steel and Coal: standardised lung function testing: lung volumes and forced ventilatory flows. Eur Respir J 1993; 6: Suppl. 16, 5-40.

16. Zapletal A, Samanek M, Paul T. Lung function in children and adolescents: methods, reference values. Prog Respir Res 1987; 22: 114-187.

17. Braggion C, Pradal U, Mastella G, Coates AL, MilicEmili J. Effect of different inspiratory maneuvers on FEV1 in patients with cystic fibrosis. Chest 1996; 110: 642-647.

18. Ingram RH Jr, Schilder DP. Effect of gas compression on pulmonary pressure, flow and volume relationships. J Appl Physiol 1966; 21: 1821-1826.

19. Cleveland WS. Robust locally weighted regression and smoothing scatterplots. J Am Stat Ass 1979; 74: 829836.

20. American Thoracic Society. Lung function testing: selection of reference values and interpretative strategies. Am Rev Respir Dis 1991; 144: 1202-1210.

21. Boczkowski J, Murciano D, Pichot MH, Ferretti A, Pariente R, Milic-Emili J. Expiratory flow limitation in stable asthmatic patients during resting breathing. Am J Respir Crit Care Med 1997; 156: 752-757.

22. Martin JG, Powell E, Shore S, Emrich J, Engel LA. The role of respiratory muscles in the hyperinflation of bronchial asthma. Am Rev Respir Dis 1980; 121: 443447.

23. Cormier Y, Lecours R, Legris C. Mechanisms of hyperinflation in asthma. Eur Respir J 1990; 3: 619624.

24. Tantucci C, Ellaffi M, Duguet A, et al. Dynamic hyperinflation and flow limitation during methacholineinduced bronchoconstriction in asthma. Eur Respir $J$ 1999; 14: 295-301.

25. Murciano D, Pichot MH, Boczkowski J, Sleiman C, Pariente R, Milic-Emili J. Expiratory flow limitation in COPD patients after single lung transplantation. Am J Respir Crit Care Med 1997; 155: 1036-1041.

26. Zinnman R, Wohl MEB, Ingram RH Jr. Nonhomogeneous lung emptying in cystic fibrosis patients. Am Rev Respir Dis 1991; 143: 1257-1261. 